\section{Buscando el vacío. Reflexiones entre líneas so- bre la forma del espacio}

Paola Gallarato *

Resumen: En el presente artículo se reflexionará acerca de la esencia de la forma. La morfología estudia la lógica de la generación y las propiedades de las formas. Cuando se piensa, estudia, investiga o se generan y modelan formas, la atención cae inevitablemente -como un instinto automático- en la articulación de los elementos sintácticos que constituye la conformación de la materia, de lo sólido, de aquello que es visible y tangible. Pero si se ajusta la escala hasta llegar a la proporción humana, es decir, se sale de una relación objetual y se empieza a explorar la forma en cuanto espacialidad recorrible, diseñada por y para el hombre, se advierte que la propia vivencia y percepción de la forma está asociada al espacio; que lo que es sólido nos permite penetrar, circular, experimentándolo físicamente y transformándolo en lugar. En esta instancia de reflexión, se propone un cambio de enfoque: ¿qué sucede si, en lugar de centrarse en la forma en cuanto sólido, en cuanto construcción y fisicidad, la atención se coloca en el hueco, en la forma del vacío que la materia misma deja libre? Lo que se plantea es un cambio de posición de observación relativa al objeto de estudio. A modo de ejercicio conceptual, se observará cómo la ubicación mental cambia -o puede hacerlo- la manera de ver la realidad y, por ende, de proyectarla.

Palabras clave: morfología - diseño - espacio - vacío - concepto - proyecto - forma - habitar.

[Resúmenes en inglés y portugués en las páginas 103-104]

${ }^{*}$ Maestranda en Lógica y Técnica de la Forma (UBA). Docente en el área de morfolgía de la FADU (UBA), carrera de arquitectura. Especialista en Lógica y Técnica de la Forma (UBA). Fotógrafa. Especialista en Fotografía de Arquitectura y Espacio Urbano - con beca total (UP). Diseñadora de Interiores (UP). Profesora de la Universidad de Palermo en el Departamento de Diseño de Espacios en la Facultad de Diseño y Comunicación.

La morfología estudia la lógica de generación y las propiedades de las formas. Cuando pensamos, estudiamos, investigamos, generamos, modelamos formas, nuestra atención cae inevitablemente, como un instinto automático, en la articulación de los elementos sintácticos que constituye la conformación de la materia, de lo sólido, de lo que es visible y tangible.

Es más, las variables de la forma -configuración, textura, brillo y transparencia- remiten todas a características o propiedades de algo sólido, matérico, concreto. 
Pero si ajustamos la escala hasta llegar a la proporción humana, es decir, salimos de una relación objetual y empezamos a explorar la forma en cuanto espacialidad recorrible, nos damos cuenta que nuestra vivencia y percepción de la forma está asociada al espacio que lo sólido permite penetrar, circular, experimentándolo físicamente y transformándolo en lugar.

Ahora bien, existe una tendencia -o quizás una resistencia- del ser humano hacia lo innombrable, lo inexistente, lo informe, lo vacío... la nada. Según la mitología lo que no está ocupado por el ser (y el ser presupone una presencia física y visible) tiene que hospedar algo oculto, del demonio, de las fuerzas del mal, incontrolables y peligrosas, misteriosas, incógnitas.

Es el histórico horror vacui, literalmente miedo al vacío, que se resuelve en llenar obsesivamente cada espacio, cada rincón, por el temor de dejarlos desocupados.

La creación y la materia son sinónimos de control, de conocimiento, de apoderamiento, de presencia indiscutida y cierta, en contraposición a una ausencia e indeterminación que deja demasiadas preguntas sin respuestas.

Asimismo, enfrentarse a la hoja en blanco detona/despierta inmediatamente la necesidad de producir, de resolver y llenar con soluciones o expresiones aquel espacio que -abandonado- es el reflejo de una no-existencia.

El diseñador frente a la página en blanco se encuentra en una situación de inestabilidad, de incertidumbre, de profunda duda, de miedo; ¿no se podría percibir ese espacio en blanco cómo el momento grávido del proyecto, percibiendo el vacío de la página como la situación que ofrece la mayor cantidad de posibilidades? Y ¿no se podría conservar ese estado de abertura, de incertidumbre a lo largo del desarrollo del proyecto, diseñando espacios pensados a partir del vacío recorrible más que de lo concreto objetual, con trazos conscientes de sus calidades porosas, flexibles, inestables, permeables?

Queremos, en esta instancia de reflexión, proponer un cambio de enfoque: ¿qué sucede si, en lugar de concentrarnos en la forma en cuanto sólido, en cuanto construcción y fisicidad, nos preguntamos o preocupamos por el hueco, por la forma del vacío que la materia misma deja libre? Lo que proponemos es trasladar nuestra posición de observación relativa al objeto de estudio, tal como describe la famosa historia del vaso medio lleno o medio vacío. Como un ejercicio conceptual, jugaremos a observar cómo nuestra ubicación mental cambia -o puede cambiar- la manera de ver la realidad y, por ende, de proyectarla. La palabra espacio evoca lo libre, lo abierto. La palabra espacio es en sí la abertura de un sitio, pero no lo podemos percibir si no está delimitado, es decir, se concreta y visualiza cuando deja de ser sí mismo. En esta expansión espacial se manifiesta un lugar, y el espacio como entidad habitable es su materialización, porque permite la presencia de lo invisible como sujeto. Este espacio, al tener un sujeto invisible, se interpreta como vacío. Pero no es un vacío que implica una carencia; tiene un cuerpo: su propia delimitación. Lo que se diseña es la materia para crear el vacío, ese mismo vacío que entendemos como espacio arquitectónico.

\section{¿Qué es más importante, el hueco o lo que lo envuelve?}

El entorno físico que constituye nuestro hábitat está compuesto por dos tipo de entidades: por un lado el medioambiente natural, biológico y orgánico determinado por nues- 
tra ubicación geográfica y, por otro lado, el conjunto de edificaciones -arquitectónicas y urbanas- que organiza, delimita, define, separa, protege, guía y ordena nuestro vivir. El primero está dado, el segundo está completa y únicamente configurado por el hombre y para el hombre.

En ese entorno se desarrollan todas nuestras actividades, desde el descanso hasta todo tipo de interacción social, el trabajo y la recreación, el estudio y todas aquellas tareas que enriquecen nuestro ser y nos empujan hacia una evolución individual y colectiva. Sin embargo, si tuviésemos que ilustrar esta descripción en un dibujo, tendríamos una imagen estática, un mapa bi o aún tridimensional de puntos $-\mathrm{A}, \mathrm{B}, \mathrm{C}$, etc.- distribuidos en un espacio cartesiano, cada uno con el nombre de la acción que hospedan como título; lo que quedaría excluido del mapa son las trayectorias de conexión entre los puntos, los recorridos, los flujos, las infinitas posibilidades con las que podríamos tejer la fábrica espaciotemporal que articula nuestras vivencias.

Si examinamos nuestra agenda podemos observar puntos en el tiempo -horas, minutos- asociados a determinadas acciones. Nuestra semana estará, entonces, compuesta por determinados puntos en el tiempo que acompañan eventos a desarrollar en determinados puntos en el espacio: citas, reuniones, encuentros, plazos de entrega, recordatorios, etc., que todos juntos generan un cuadro congelado, estable, determinado y fijo. $\mathrm{Si}$, al mismo tiempo, observamos nuestro entorno construido, podemos observar que la forma de las casas, de los edificios, de la ciudad, de la red de conexiones que nos lleva desde el punto A hasta el punto B y de todo lo que constituye nuestro hábitat -en su gran mayoría- tiene las mismas cualidades formales de ortogonalidad, estabilidad, determinación, solidez.

Con este propósito, el arquitecto japonés ToyoIto, un día, desde el cielo sobrevolando Marruecos, reflexionó sobre la naturaleza de la arquitectura clásica mirando las rectas racionales de una autopista y comparándolas con un río que fluía a su lado. Pensó entonces en el hombre vitruviano dibujado por Leonardo, perfectamente inscripto en las figuras geométricas primarias, símbolo de la razón y prueba de su capacidad de comprender y medir el universo: toda la arquitectura, hasta Le Corbusier y Mies Van der Rohe incluidos, había sido concebida partiendo de un orden geométrico, que tenía como modelo el cuerpo humano en su noción de proporciones fijas y estáticas (Ito, 2000, p. 59). Por el contrario, ese río demostraba una naturaleza bien distinta: "Varios surcos de agua fluían en medio del desierto sin que la mano del hombre los hubiera tocado en absoluto. Cada uno de ellos formaba grandes meandros constantemente. Ninguno describía una línea recta”. (Ito, 2000, p. 68)

Considerando que el cuerpo humano está aproximadamente compuesto por el $60 \%$ de agua, "si el modelo ideal de la arquitectura clásica se apoyaba en esta concepción estática del cuerpo, $\dot{i}[\ldots]$ en qué puede apoyarse una arquitectura que considera al cuerpo humano como un sistema de fluidos?" (Ito, 2000, p. 71)

Efectivamente, más allá de la grilla espacio-temporal que nos orienta, ordena y organiza, nuestro habitar se asemeja en mayor grado al fluir líquido de un río que busca incesantemente el espacio vacío por donde pasar: en esta imagen los puntos anteriormente descriptos podrían tomarse como pequeños puertos de referencia a lo largo del camino, pero lo determinante, lo esencial estaría configurado por los infinitos puntos que conectan aquellos que tomamos como referencia: es el panta rei heracleo en perpetua transformación. 
Con respecto a esto, Bauman (2000) relata el pasaje de la modernidad sólida a la modernidad líquida, término que enlaza las reflexiones de ToyoIto sobre los límites difusos en arquitectura, tejiendo un puente entre el enfoque sociológico y el enfoque espacial y proyectual; ambos ayudan a comprender la naturaleza tan difícil de definir de la mutación que está ocurriendo en las últimas décadas en la concepción de nuestra manera de habitar. Bauman describe el significado de ser moderno en la actualidad como el "ser incapaz de detenerse y menos aún de quedarse quieto" estando perpetuamente "un paso delante de uno mismo, en estado de constante trasgresión". (2000, p. 34)

ToyoIto (2000) recuerda que según la teoría de planificación de la Era Moderna, la diversidad y la complejidad de las acciones humanas se resumen en unos conceptos funcionales simples y abstractos, que corresponden a espacios determinados; de aquí se dedujo racionalmente que la forma sigue la función. Sin embargo, esta operación racional -dice- tenía como objetivo extraer el mundo interno puro, ordenado, a partir del mundo externo caótico:

[...] la teoría de planificación de la era moderna podía constituirse, por vez primera, por este acto de separar los límites exterior e interior de una manera clara" (2000). Más clara era tal separación, más funcional resultaba la arquitectura, "teniendo al mismo tiempo un carácter finito. Porque cuando una máquina está fabricada con un objetivo determinado, cuanto más se aferre a un sistema cerrado y concluido mejor funciona con alta eficiencia. (Ito, 2000, p. 206)

ToyoIto (2000) encuentra una representación de las características cerradas e individualistas de los edificios que brotan en las ciudades contemporáneas en la imagen del tren bala, medio de transporte privilegiado que se desplaza sobre su andén aislado, separado de las otras rutas, asegurando la optimización del tiempo para viajar desde un punto A hacia un punto B. Sin embargo, la complejidad de las actividades humanas se parece mucho más al rizoma deleuziano que a la linealidad del tren bala; ToyoIto pone así en discusión la coherencia entre las tendencias arquitectónicas que critica con la imagen metafórica del medio de transporte, símbolo de la era moderna, y el proceso transformativo rizomático con falta de un eje central y de definición propio de la vida contemporánea.

Paralelamente a su crítica hacia las conexiones inexistentes entre arquitectura y su entorno, ToyoIto lleva las mismas observaciones adentro de los edificios, en donde cada ambiente está pensado para una determinada función, forzando así el desarrollo de "actos unilaterales" (Ito, 2000), es decir, de acciones humanas que no se mezclan entre sí. A estos fines, se dividen los espacios interiores por medio de paredes que aseguran la correcta ejecución de cada función a la cual están destinados, sin interferir con las demás del otro lado.

Si consideramos las acciones humanas como un eterno fluir por los espacios e intersticios de nuestro entorno, al proyectar el mismo ¿no se debería priorizar la forma de esos espacios, los vacíos por lo que se transita o permanece, las arterias que los conectan y enlazan y dejar que la materia se ablande al paso del flujo, se amolde, se ajuste, se doble, resista o ceda, acompañe, invite, sugiera, atrape...? 


\section{La forma del espacio}

Deberíamos coincidir unánimemente que el espacio está siempre alrededor nuestro o, más aún, que nosotros estamos permanentemente inmersos en él. Pero, ¿qué forma tiene el espacio?

A través de su mirada fenomenológica Heidegger (1997) considera el espacio inherente a la noción de Dasein -literalmente Ser-Ahí, es decir el hombre es el lugar, $D a$ - ahí, donde el Ser-Sein, se manifiesta- refiriéndose al modo cotidiano de estar siendo continuamente en relación con las cosas del mundo; afirma además que "ni el espacio es en el sujeto ni el mundo es en el espacio" (1997, p. 116), ya que el sujeto mismo, o sea la realidad humana, el ser ahí, es espacial en su propia naturaleza. Y es espacial porque, en su ser-en-el-mundo, en sus relaciones con las cosas del mundo, está continuamente influenciado por la cercanía o lejanía de (las cosas) útiles, o sea, por el conjunto de posibles relaciones que la intuición formal del espacio no llega a descubrir y explicar en las distintas disciplinas geométricas.

Cuando se habla de hombre y espacio, oímos esto como si el hombre estuviera en un lado y el espacio en otro. Pero el espacio no es un enfrente del hombre, no es ni un objeto exterior ni una vivencia interior. No existen los hombres y además espacio porque cuando digo 'un hombre' y pienso con esta palabra en aquél que es al modo humano -es decir: que habita- entonces con la palabra 'un hombre' ya estoy nombrando la residencia. [...] La relación del hombre con los lugares y a través de los lugares con espacios, descansa en el habitar. El modo de coexistencia de hombre y espacio, no es otra cosa que el habitar pensado de un modo esencial. (Heidegger, 1951, p. 70)

Ahora volvamos a la forma del ese espacio: imaginemos estar en una pradera, o en el medio del mar, en el desierto, en la pampa infinita, en una pista de ski: ¿podríamos describir qué forma tiene ese espacio? ¿Podríamos reconocer sus cualidades, su tamaño, sus características, definir sus límites? Muy probablemente no.

Imaginemos ahora estar en una catedral gótica, en el medio de la nave principal: esta vez, frente a la misma pregunta, nuestra mente se llenaría de adjetivos como inmenso, alto, enorme, etc. Podríamos también decir que allí las dos dimensiones horizontales sucumben a la dimensión vertical, porque la intención de ese espacio es la de provocar una succión hacia arriba sobre los individuos que lo visitan. Podríamos asimismo decir que el nivel de transparencia es casi nulo, con excepción de los ventanales que dejan penetrar la luz del exterior de manera finamente controlada y siempre desde arriba. Podríamos estudiar su volumetría, la relación entre las proporciones, las características de sus superficies. En fin, seríamos capaces de analizarlo y describirlo.

¿Cuál es la diferencia? En el primer caso, el espacio que nos rodea es tan grande que no podemos construir una correspondencia directa con nuestras dimensiones, no hay relación de escala, nos excede. En el segundo, estamos envueltos por un espacio que ha sido pensado, construido y estudiado para nosotros con el objetivo de generar una precisa influencia sobre nuestro estado de ánimo, relacionada con una cierta visión de espiritualidad. Particularmente en este último caso, lo que prevale por sobre todo -estructura, 
materiales, elementos decorativos, en fin, la parte sólida y concreta- es el espacio, que ha sido dejado vacío para que su efecto sea lo más directo posible. Hasta los elementos portantes, los contrafuertes, que aseguran estabilidad dada la excepcional altura, están afuera, liberando y despojando el interior.

El espacio es como un líquido, su forma depende del contenedor. Ahora bien, en nuestro enunciado inicial, la morfología estudia la lógica de generación y las propiedades de la forma, entendiendo esta como forma abstracta o entitativa, forma arquitectónica y forma urbana, donde lo diferente en cada caso es la escala.

Si hablamos de morfología entitativa -usualmente estudiada en morfología general y asociada al diseño industrial- la escala es objetual, es decir la relación entre lo generado y el sujeto es instrumental a la interacción de este con el objeto proyectado en cuanto utensilio. Cuando, por el contrario, pasamos al espacio, es decir, nos ocupamos de formas recorribles, que podemos atravesar, inmediatamente nuestra relación con lo generado es distinta y ya no puede ser considerada objetual. Obviamente los fundamentos de la morfología aplican a todos los casos, aunque los separan lógicas proyectuales profundamente distintas, donde la bisagra está dada por un cambio de enfoque: en el primer caso el énfasis está puesto sobre el objeto sólido, concreto, mientras que en el segundo caso la atención debería poderse desplazar hacia el hueco, al espacio habitable y a sus redes de conexión. Sin embargo, es muy común observar una cierta objetualidad en la forma de proyectar nuevos edificios, nuevos espacios, nuevos lugares.

El proyectista -arquitecto o diseñador- cumple una doble función, encarna un dúplice rol: por un lado es Dios, es quien prefigura lo que todavía no existe, quien posee el poder de modificar nuestro entorno habitable junto con nuestra manera de hacerlo, cambiar nuestras costumbres e inventar nuevas posibilidades. Por otro, lado también es ser humano, es usuario, es quien recorre, quien atraviesa y permanece, habitando aquellos espacios que conforman el cauce de nuestro fluir. Este segundo rol muy a menudo se olvida: el resultado son objetos construidos, utensilios fuera de escala cuyos espacios son mera consecuencia de la prepotencia formal de sus líneas, planos y volúmenes concretados y que lo ocupan.

Hasta aquí nuestro concepto de espacio va ligado a la caja. Sin embargo, se comprueba que las posibilidades de alojamiento que constituyen el espacio de la caja son independientes de qué grosor tengan las paredes. ¿No se puede hacer que el grosor descienda a cero sin que al mismo tiempo se eche a perder el espacio? La naturalidad de este proceso de paso al límite es evidente, subsistiendo ahora en nuestro pensamiento el espacio sin caja, una cosa independiente que, sin embargo, parece tan irreal cuando se olvida la procedencia del concepto. (Einstein, 1979, p. 16)

Volvamos ahora rápidamente al habitar entendido como flujo, como líquido: según se lee en la Enciclopedia Británica lo que distingue los líquidos de los sólidos es que "en descanso, no pueden sostener una fuerza tangencial o cortante" y, por lo tanto, "sufren un continuo cambio de forma cuando se los somete a esa tensión" (Bauman, 2000, p. 6). Así el sociólogo Zygmunt Bauman introduce su discurso sobre la modernidad líquida, analizan- 
do metafóricamente las características físicas de la fluidez y reconociendo en el comportamiento de los líquidos un paralelo con el movimiento de la sociedad contemporánea. "Los líquidos - dice Bauman- a diferencia de los sólidos, no conservan fácilmente su forma. Los fluidos [...] no se fijan al espacio ni se atan al tiempo" (2000, p. 7). Los sólidos poseen una clara definición espacial pero "neutralizan el impacto y disminuyen la significación del tiempo" (Bauman, 2000, p. 7), es decir, resisten su transcurrir o vuelven irrelevantes sus efectos; los fluidos no pueden conservar una forma determinada y tienden a cambiarla con el transcurrir del tiempo; por consiguiente, "para ellos lo que cuenta es el flujo del tiempo más que el espacio que puedan ocupar: ese espacio que [...] solo llenan por 'un momento'. En cierto sentido los sólidos cancelan el tiempo; para los líquidos, por el contrario, lo que importa es el tiempo". (Bauman, 2000, pp. 7-8)

El tiempo, entonces, entra en juego para subrayar más fuertemente aún la distinción entre arquitectura objetual y arquitectura espacial: es la cuarta dimensión que completa, a pesar de nuestra limitada forma mentis, el tejido espacio-temporal que nos constituye como seres humanos.

Si la arquitectura objetual construye, la arquitectura espacial se preocupa por el vacío al que la primera renuncia.

\section{Perderse}

“Quien pierde tiempo gana espacio”. (Careri, 2006, p. 52)

Antes de inventar la arquitectura, el hombre poseía una manera simbólica de transformar el espacio: caminar. El acto de caminar como fin en sí mismo, bien distinto del funcional trasladarse apresurado y cegado que conecta nuestras tareas diarias, es un ejercicio activo y profundamente creativo: nos permite apoderarnos visual y físicamente de nuestro entorno, descubrirlo y dejarnos afectar por él, conectar y multiplicar los puntos que corresponden a los instantes intermedios, explorar lo que subyace entre líneas, las pausas entre las notas. Deleuze y Guattari(1997) lo llamaron el trayecto nómada, describiéndolo como aquella acción que a pesar de seguir "pistas y caminos habituales, su función no es la del camino sedentario, que consiste en distribuir a los hombres un espacio cerrado, asignando a cada uno su parte y regulando la comunicación entre las partes. El trayecto nómada hace lo contrario, distribuye los hombres [...] en un espacio abierto, indefinido, no comunicante". La caminada nómada permite al tiempo de volverse elástico, de estirarse y contraerse, y al mismo tiempo transforma el espacio en un laberinto misterioso donde las rectas se ablandan, ramificándose en múltiples posibilidades.

Francesco Careri, en su Walkscapes (2006) dice que la ciudad "descubierta por los vagabundeos de los artistas es una ciudad líquida, un líquido amniótico donde se forman de un modo espontáneo los espacios otros, un archipiélago urbano por el que navegar caminando a la deriva: una ciudad en la cual los espacios del estar son como las islas del inmenso océano formado por el espacio del andar".

Si pudiésemos registrar con un sensor en un plan nuestros desplazamientos durante las 24 horas y superponerlos todos en un único gran mapa filmado tendríamos la imagen en tiempo real del flujo -o fluir- urbano, así como tendríamos también el registro de la 
forma de los cauces -o vacíos- que configuran los espacio en los que constantemente nos movemos.

Recuperar el caminar como acto de conocimiento es vital para todos seres humanos: resulta mucho más fácil y natural cuando estamos en un lugar que no conocemos porque -en ese caso- no estamos condicionados ni saturados por impresiones que vemos todo el tiempo. Sin embargo, una pequeña desviación de la ruta acostumbrada, un cambio de calle o de colectivo en los traslados cotidianos, pueden desvelar rincones y esquinas, sombras y acentos, colores, lugares que sorprenden e inspiran. Un increíble ayudante para desarrollar este cambio de hábitos y despertar de la vista, es llevar consigo una cámara: el "tercer ojo" pide constantemente el esfuerzo de seleccionar lo que va a estar congelado en el tiempo, el encuadre esencial... y para poder seleccionar es necesario tener una mirada atenta y consciente.

Recorrer nuestros espacios con atención es -hemos dicho- vital para todos, pero más aún para los proyectistas: ellos son los encargados de modificar lo existente, de cambiar el entorno y/o la manera de vivirlo, de actualizarlo y desarrollarlo para que nosotros -los usuarios- podamos aprovecharlo y enriquecernos a través de él. Resulta imperante y necesario, por lo tanto, que aquellos que se ocupan de prefigurar nuestro entorno, tengan en cuenta dos puntos: por un lado conocerlo, lo que significa mirarlo, verlo, estudiarlo; por otro lado deben poder imaginarse sus posibilidades, entrever sus mejoramientos, postulando hipótesis y variantes, siendo Dios y hombres a la vez. Y todo parte del espacio vacío, por el que caminan con ojos y mentes abiertas.

De lo contrario, en el panorama que nos rodea, se corre el riesgo de perpetuar ciertos vicios: que nuestro entorno se expanda sin conciencia y por mano de un copy-paste que no se postula preguntas y busca únicamente responder a las leyes del mercado y de la especulación edilicia; que los lugares de nuestro hábitat sean simples cajas contenedoras que se repiten al infinito, "ortogonalizando" nuestra manera de pensar al mismo tiempo; $y$, que aquellos que se ocupan de espacios se queden en un plano decorativo y de ambientación, en lugar de generar transformaciones conceptuales capaces de modificar y actualizar nuestros dispositivos habitacionales.

Un proyectista no deja nunca de prefigurar.

En realidad, el nomadismo siempre ha vivido en ósmosis con el sedentarismo, y la ciudad actual contiene en su interior tanto espacios nómadas (vacíos) como espacios sedentarios (llenos), que viven unos junto a los otros en un delicado equilibrio de intercambios recíprocos. La ciudad nómada vive actualmente dentro de la ciudad sedentaria, se alimenta de sus desechos y a cambio ofrece su propia presencia como una nueva naturaleza que sólo puede recorrerse habitándola. (Careri, 2006, p. 24)

\section{Señales de cambio}

Las ciudades son capas de historia, piedras y ladrillos dejados en otros tiempos, por otras manos, espejos de mundos parecidos al nuestro, pero profundamente distintos. 
Intervenir en aquellos espacios, en aquellos huecos que el tiempo nos ha dejado no es tarea sencilla y se puede dar a través de dos tipos de intenciones diferentes: puede ser una intervención de reparación-restauro o modificación, cuya estrategia proyectual es seguir el mismo lenguaje de lo existente, o puede ser una intervención que articula el lenguaje contemporáneo a lo histórico, generando así un contraste formal y estético. En los dos casos es imprescindible penetrar en profundidad en el tejido de capas, conocerlas, y de allí comenzar el diálogo, sea eso de continuidad o de choque.

Queremos, en esta instancia, examinar brevemente tres ejemplos que han -de una forma u otra- logrado establecer ese diálogo, partiendo del espacio, del vacío, de la experiencia del recorrido, del flujo, del movimiento, de la cuarta dimensión.

\section{El Museo Judío de Berlín - Daniel Libeskind}

Difícilmente podamos encontrar un sujeto tan paradigmático para nuestras reflexiones, ya que se ocupa de dar forma al vacío, a la ausencia que el Holocausto de la Segunda Guerra Mundial ha dejado plasmada en el tiempo. La obra de Libeskind está ubicada -e íntimamente entrelazada- con el antiguo museo judío construido en el 1933 y cerrado luego por el gobierno nazi. El desafío era inmenso: la nueva construcción tenía no solamente que hospedar muestras y archivos históricos, sino que debía en sí, ser el manifiesto de una experiencia, ser el testigo concreto de la memoria.

El lenguaje arquitectónico elegido es contemporáneo, posmoderno para algunos, con una volumetría rígida y esencial, casi cortante. La característica principal, sin embargo, de la intervención no es la forma del objeto arquitectónico, sino que reside más bien en las cualidades espaciales que manipulan y afectan a quien lo atraviesa: el fluir del recorrido está constantemente interrumpido por obstáculos y momentos de pausa, de reflexión, de contemplación, sean esos escaleras que bajan hacía la oscuridad, pasillos que terminan en la nada, bosques de columnas de hormigón apoyadas a un piso que no está en plano y que impide la estabilidad de los pasos. Pero, por sobre todo, el zigzagueo que se observa en planta está entrecortado por los que, en mi opinión, son los elementos más atrevidos y poderosos de todo el proyecto: se trata de 6 torres de concreto que atraviesan el edificio en toda su altura, volúmenes aparentemente ciegos, iluminados únicamente por medio de claraboyas. Su interior está completamente despojado y no hay accesos; Libeskind los llama los vacíos y encarnan la forma última de los judíos en Berlín: la ausencia. Los vacíos simbolizan el rechazo de ceder a la nostalgia, la negación misma de la idea de museo: no hay nada para ver a través de las sutiles ventanas que se asoman al interior, con excepción tal vez de la cara sorprendida de algún visitante (Copans, 2002). Se puede imaginar cuánto debe haber sido complicado convencer a los burócratas para que inviertan dinero para construir espacios que eran inutilizables -en un sentido económico-comercial-y sin embargo, esos vacíos son la representación formal de una ausencia que nunca podrá volver a aparecer, de un espacio que jamás se podrá colmar.

El último vacío es el único al que se puede acceder, llamado el vacío de la memoria (Ver Figura 1 en p. 100): el visitante que lo atraviesa debe pisar caras de hierro como si fueran candados; el silencio se llena del ruido estridente provocado por cada paso. 


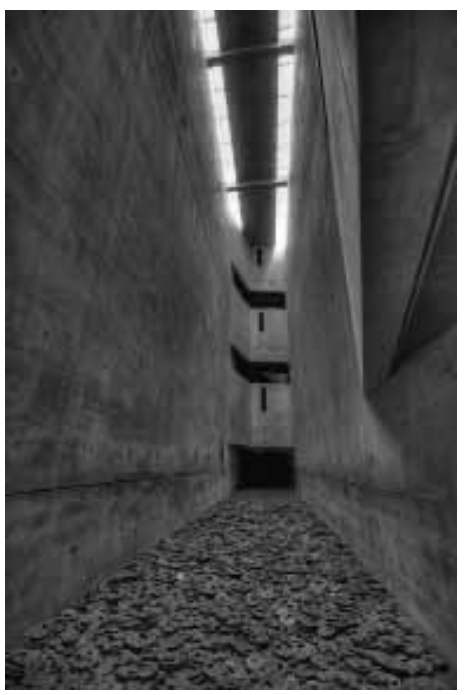

Figura 1. http://kberry.wordpress.ncsu.edu/2012/11/13/4/

\section{La Mediateca de Sendai - ToyoIto}

El proyecto de la Mediateca de Sendaï es un ejemplo de espacio líquido no solamente por sus características estéticas inmediatas sino, y sobre todo, por el proceso conceptual que ha permitido la concreción del edificio.

ToyoIto (2000) reconoce una, por así decirlo, doble vida de la Mediateca desde su comienzo: por un lado estaba el edificio concreto, en vía de construcción, por el otro, estaba la planificación de lo que iba a pasar adentro de ese edificio que aún no existía. El debate sobre las actividades, los talleres, las distintas funcionalidades permanecía constantemente abierto: el dinamismo de los intercambios y de las discusiones atrajo la atención internacional, instaurando un seminario público orgánico y maleable, origen de nuevos debates y nuevas ideas. Normalmente, un edificio público de esa envergadura hubiese tenido planteados y establecidos desde el principio la mayoría de los detalles de su organización interior con las correspondientes especificaciones técnicas. La naturaleza libre del proyecto tomó vida ya años antes que el edificio fuese completado y todavía sigue vigente: este aspecto constituye la verdadera esencia de la Mediateca y es representativo de su ser líquida, es decir preparada y disponible para futuras transformaciones.

Para ToyoIto la arquitectura "expresa un orden muy artificial" (Copans, 2004); para contrastar ese orden, él quiso "que los siete niveles fuesen apilados uno sobra el otro, sin un orden particular [...] como si siete edificios pudiesen coexistir juntos, estableciendo una relación entre ellos que fuese totalmente igualitaria, libre". (Copans, 2004)

Aparece aquí el elemento juego -ya reconocido por Gadamer (1991) como una de las justificaciones antropológicas de la experiencia estética porque parte constituyente de la naturale- 
za del ser humano- en donde, si bien siguiendo una coherencia con las intenciones iniciales, que se pueden identificar con las reglas del juego, el proyectista se permite experimentar y jugar con formas nuevas, dejándose sorprender por las mismas, acompañando el flujo creativo y permaneciendo permeable a las variaciones orgánicas provenientes del exterior. Si se observan los bocetos de los planos de cada piso, el juego resulta evidente (Ver Figura 2).

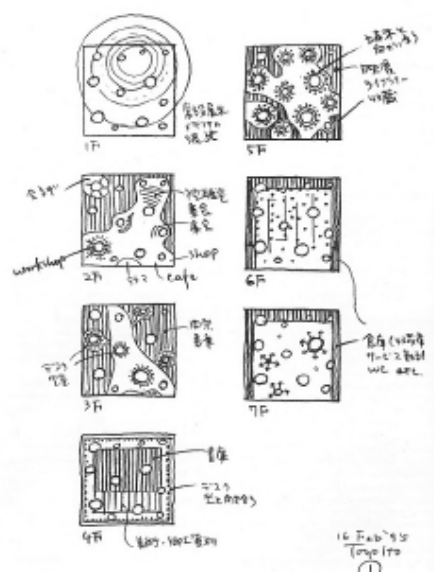

Figura 2. SMT (2010): Sendai Mediatheque, sitio oficial. Disponible en: http://www.smt.city.sendai.jp/en/info/office/2008/0305/

Más allá de la lectura diagramática de los bocetos, se intuyen la libertad de la subdivisión de los espacios, la diversificación de las plantas, la organicidad de la zonificación y, sobre todo, resulta evidente el aspecto lúdico de los espacios, abiertos y flexibles a alteraciones. "Por supuesto existen áreas dedicadas a funciones específicas", dice ToyoIto, "pero yo quería enfatizar los espacios en blanco, las áreas sin etiquetas", como los pasillos, los vestíbulos, las antecámaras; "yo atribuyo la mayor importancia a estos espacios indefinidos, dejando lugar para usos futuros a los cuales nadie pensó cuando el edificio fue construido" (Copans, 2004). La liquidez del espacio pensado por el arquitecto, entonces, no es solamente una característica tridimensional, morfológica o material: no se queda en una imitación fotográfica que quiere representar -en sólido- el movimiento de lo líquido; la fluidez de este espacio se extiende a la cuarta dimensión: el tiempo. Es ahí donde el flujo se libera, en el considerar las posibles transformaciones que algo orgánico recorre a través de su desarrollo temporal.

\section{Metropol Parasol - Jürgen Mayer-Hermann}

Ubicado en la Plaza de la Encarnación, en pleno centro histórico de Sevilla, es una estructura en madera entre las más grandes del mundo, compuesta por 6 parasoles llamados Setas 
que se asemejan a hongos gigantes. La inserción de esta morfología de manual en el tejido urbano instaura un diálogo orgánico, natural, delicado entre la contemporaneidad y las capas históricas que la rodean: la escala, el juego de sus formas irregulares, el equilibrio entre la grilla geométrica de su planta con la suavidad de sus curvas, la porosidad de su trama se entrelazan con la ciudad. Sus intersticios nos llevan como cavernas a descubrir el Antiquarium que hospeda los restos de los cimientos romanos y moriscos, nos llevan hacia arriba, para respirar a 360 grados los techos de Sevilla, el Guadalquivir, los barrios, las calles, los hitos. En cada momento del recorrido parece que la forma arquitectónica se convierte en plastilina para dejarnos fluir libres, como una manta líquida y maleable, y en verano el parasol cumple su función primaria, protegiendo a los transeúntes de los 50 grados al sol. Las pasarelas de las terrazas acompañan cada curva (ver Figura 3), se doblan, se bifurcan, se reúnen, se pierden y vuelven a encontrarse en un juego liviano que cambia constantemente el punto de vista de quien se deja sorprender frente a una nueva perspectiva a cada giro. Toda la estructura danza y se transforma, renovando su diálogo a cada paso con la plaza que la hospeda, revelando la multiplicidad de los recovecos como un organismo en perpetua transformación.

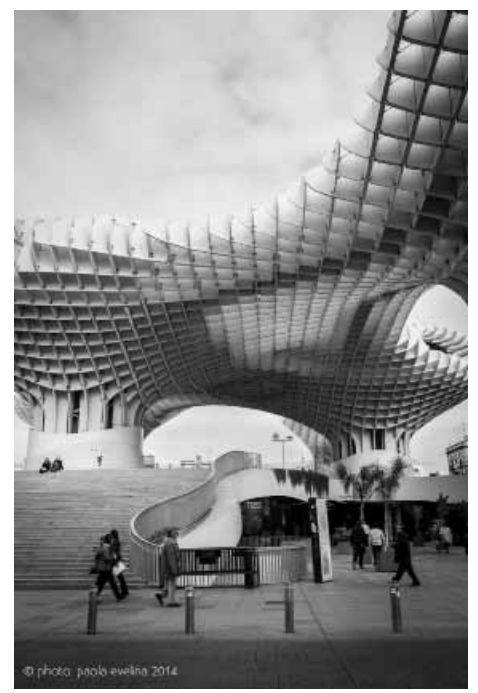

Figura 3. Elaboración propia

\section{Conclusiones}

Estas reflexiones han tenido la intención de ampliar un poco la mirada, como así también jugar con los límites del espacio proyectual, postulando un cambio de enfoque, de punto de vista. 
También han querido recordar que diseñar es mucho más que aplicar estilos y/o estéticas existentes a un proyecto: diseñar es una tarea mucho más profunda y compleja, cuyos efectos pueden ser tan determinantes cuanto más se lo tome con responsabilidad y conciencia. Y finalmente, concluiremos con una frase de Montaner (1993, p. 3) quien dijo que el ensayo, "entendido como indagación libre y creativa, no exhaustiva ni especializada, sin un carácter rigurosamente sistemático, es la más genuina herramienta de la crítica”. Y agrega que el ensayo, como forma de análisis y de reflexión, "debe basarse en plantear preguntas, mostrando la arbitrariedad de las convenciones" y "consiste en una reflexión abierta e inacabada que parte del desarrollo de la duda". Tal estructura abierta permite relacionar y entrecruzar referencias que se extienden a todos los campos de la cultura, ampliando el horizonte del conocimiento humano gracias a una mirada trasversal y abarcadora.

\section{Bibliografía}

Bauman, Z. (2009). Modernidad Líquida, Buenos Aires: Fondo de Cultura económica.

Careri, F. (2006). Walkscapes. Camminare come pratica estética. Torino: Giulio Einaudi Editore.

Copans, R. (Director). (2004). La Mediatheque de sendai. [Documentary]. Coproducción ARTE France, Les Films d'Ici, Le centre Pompidou.

Copans, R.; Neumann, S. (Directores). (2002). Le MuséeJuif de Berlin. Entre les lignes. [Documentary]. Coproducción ARTE France, Les Films d'Ici, Le centre Pompidou.

Deleuze, G.; Guattari, F. (1997): Mil mesetas. Capitalismo y esquizofrenia. Valencia: PreTextos.

Heidegger, M. (1951). Construir, Habitar, Pensar. Conferencia.

Ito, T. (2000). Escritos. Murcia: Colegio de Aparejadores y Arquitectos Técnicos de Murcia. Ito, T. (2000). Mediateca de Sendai. Informe sobre su proceso de construcción. Murcia: Colegio de Aparejadores y Arquitectos Técnicos de Murcia.

Montaner, J. M. (1999). Arquitectura y crítica. P. 3. Barcelona: Gustavo Gili.

Zevi, B. (1979): Frank Lloyd Wright.Bologna: Zanichelli.

Summary: In this article we will ponder on the essence of form. Morphology studies the logic that lies behind the generation and properties of shapes.

When we think, study, or research how modeled forms are shaped, the attention inevitably falls -as an automatic instinct- on the articulation of those syntactic elements that constitute the creation of matter, of what is solid, visible and tangible. But if we adjust the scale until we match human proportions, leaving that objectified relationship and beginning to explore the shape as a spatiality that can be walked through, designed by and for men, we will realize that the experience itself and the way it is perceived are associated with space, with that void that is left for us to penetrate, to circulate, physically experiencing and transforming it into a place. At this point we suggest a change in our point of view: what if, instead of focusing on shapes as a solid, as a structure and physicality, we place 
our attention on what is hollow, on the shape of that void that matter itself leaves empty, unoccupied? We propose to change our position in relation to the object we study. As a conceptual exercise, we can observe how our mental location can change the way we view reality and, therefore, our way to modify it through our planning activity.

Key words: morphology - design - space - void- project - form - inhabit.

Resumo: Este artigo reflete sobre a essência da forma. A morfologia estuda a lógica da geração e as propriedades das formas.

Quando se pensa, estuda, pesquisa ou se geram e modelam formas, a atenção cai inevitavelmente, como um instinto automático, na articulação dos elementos sintáticos que constitui a conformação da matéria, do sólido, de aquilo que é visível e tangível. Mas se a escala se ajusta até chegar à proporção humana, é dizer, se sai de uma relação objetual e se começa a explorar a forma em quanto espacialidade possível de percorrer, desenhada por e para o homem, adverte-se que a própria vivencia e percepção da forma está associada ao espaço; que o que é sólido nos permite penetrar, circular, experimentando-o fisicamente e transformando-o em lugar. Nesta instancia de reflexão, se propõe uma troca de enfoque: que acontece se, em lugar de centrar-se na forma em quanto sólido, em quanto construção e fisicidade, a atenção coloca-se no buraco, na forma do vazio que a matéria mesma deixa livre? Se pranteia uma mudança de posição de observação relativa ao objeto de estudo. A modo de exercício conceitual se observará como a localização mental muda, ou pode fazelo, a maneira de ver a realidade, e, portanto, de projetá-a.

Palavras chave: morfologia - design - espaço - vazio - conceito - projeto - forma - habitar. 